\title{
Diagnóstico ambiental qualitativo no "lixão" da cidade de Pombal, Paraíba
}

\section{Qualitative Environmental diagnosis in the "dumpsite" of city Pombal, Paraíba}

\author{
Naiara Angelo Gomes ${ }^{1 *}$, José Cleidimário Araújo Leite ${ }^{2}$, Camilo Allyson Simões de Farias ${ }^{3}$, Ana Paula Oliveira Silva ${ }^{4}$; \\ Fernanda Carolina Monteiro Ismael ${ }^{5}$
}

Resumo: A destinação ambientalmente inadequada de resíduos sólidos urbanos provoca diversos impactos negativos no meio ambiente, especialmente nos componentes ambientais: solo, água e ar atmosférico. Neste sentido, para que esses efeitos adversos sejam identificados, é necessário conhecer as características do ambiente na área em questão. Neste estudo, objetivouse a elaboração de um diagnóstico ambiental qualitativo dos meios físico, biótico e antrópico da área do lixão da cidade de Pombal, Estado da Paraíba. A metodologia utilizada teve por base consultas a órgãos públicos, pesquisas bibliográficas, visitas de campo e fotodocumentação. De acordo com os resultados, verificou-se a ocorrência de várias alterações ambientais adversas significativas nos meios físico, biótico e antrópico, típicas da destinação ambientalmente inadequada de resíduos sólidos em "depósitos" a céu aberto, o que tem resultado em uma degradação ambiental local e acarretado danos sociais, sanitários e ecológicos para o município.

Palavras-chave: Resíduos sólidos urbanos; Destinação inadequada de resíduos; Degradação ambiental; Meio ambiente.

Abstract: Environmentally inadequate disposal of municipal solid waste causes many negative impacts on the environment, especially in the environmental components: soil, water and atmospheric air. Then, for these adverse effects were identified, it is necessary to know the characteristics of the environment in the area in question. This study aims to develop a qualitative environmental diagnosis of the physical, biotic and anthropic environment of the dumpsite of Pombal in state of Paraíba, Brazil. The methodology used in the study was based on consultations in government agencies, bibliographic research, field visits and photo documentation. According to the results, it were noted the occurrence of a number of significant adverse environmental changes in the physical, biotic and anthropic environment, typical of solid waste disposal in "deposits" at openwork, which has resulted in a local environmental degradation and have caused social, health and ecological damage to the municipality.

Keywords: Municipal solid waste; Inadequate disposal of waste; Environmental degradation; Environment.

\footnotetext{
*Autor para correspondência

Recebido para publicação em 14/11/2016; aprovado em 15/01/2016

${ }^{1}$ Mestranda em engenharia Civil e Ambiental, Universidade Federal de Campina Grande, Campina Grande - PB; (83) 99835-6056, naiaraangelocz@hotmail.com.

${ }^{2}$ Prof. Dr. em Engenharia de Processos, Universidade Federal de Campina Grande, cleidimari@ ccta.ufcg.edu.br.

${ }^{3}$ Prof. Dr. em Engenharia Civil, Universidade Federal de Campina Grande, camilo@ccta.ufcg.edu.br.

${ }^{4}$ Graduanda em Engenharia Ambiental, Universidade Federal de Campina Grande, paulinhacatole@ hotmail.com.

${ }^{5}$ Profa. Ma. em Sistemas Agroindustriais, Instituto Federal de Educação, Ciências e Tecnologia da Paraíba, fernanda_monyeiro@hotmail.com.
} 


\section{INTRODUÇÃO}

A geração de Resíduos Sólidos Urbanos (RSU) no Brasil Localização e caracterização geral da área de estudo aumentou 2,9\% de 2013 a 2014 (ABRELPE, 2014), e os principais fatores que têm contribuído para este aumento são o crescimento populacional e econômico, e ainda o consumismo "exagerado" por parte da população.

De acordo com a ABRELPE (2014), no Brasil, foram gerados cerca de 78,6 milhões de toneladas de RSU durante o ano de 2014, em que a região Nordeste foi responsável pela produção de $22,2 \%$ desse total. Com relação à destinação final, cerca de $31,3 \%$ dos RSU gerados na região Nordeste são dispostos em locais inadequados e a céu aberto, denominados popularmente de "lixões".

Os RSU são formados por resíduos de diversas origens, tais como: domésticos, varrição de ruas, de poda de árvores, de borracharias, supermercados entre outros (SILVA, 2012). Quando estes resíduos são coletados e dispostos em locais inadequados, a tendência é haver uma mistura que, em conjunto com processos naturais (precipitação, ação de microrganismos, vento etc.), ocasiona diversos danos ao meio ambiente (solo, água, ar, flora, saúde pública, economia, sociedade entre outros).

Para a avaliação ambiental de áreas alteradas pela ação antrópica, a exemplo de áreas de lixões, é necessária a elaboração de estudos ambientais, que podem incluir desde o diagnóstico ambiental da área até o Plano de Recuperação de Áreas Degradadas (PRAD), sendo o primeiro, uma base para a confecção e execução do segundo. O diagnóstico tem por finalidade principal descrever e analisar a situação ambiental atual de um área na qual, em geral, haverá a implementação de um empreendimento ou outra atividade antrópica.

Na Resolução CONAMA n. 001/1986, em seu Art. 6, Inciso I, define-se diagnóstico ambiental como:

A completa descrição da área de influência do projeto e análise dos recursos ambientais e suas interações, se necessário, de modo a descrever a situação ambiental da área, antes da instalação de um projeto, considerando: o meio físico, o meio biológico e o meio socioeconômico (BRASIL, 1986, p. 3).

Com base no exposto, destaque é dado ao lixão da cidade de Pombal, que se encontra localizado nas proximidades da área urbana desse município e foi implantado há cerca de 15 anos para disposição dos resíduos sólidos produzidos na cidade (AZEVEDO, 2014).

Estudos realizados por Lucena (2013) e Azevedo (2014) na referida área do lixão abordaram, respectivamente, de forma geral, temas como identificação preliminar de impactos ambientais, diagnóstico ambiental simplificado e degradação ambiental. No entanto, a quantidade resíduos na área de abrangência do lixão têm aumentado, o que torna necessário a elaboração de um diagnóstico ambiental qualitativo mais abrangente para a área de influência direta desse lixão, que venha contribuir com pesquisas futuras voltadas à recuperação da área de implantação desta atividade no citado município.

Com base no exposto, objetivou-se elaborar um diagnóstico ambiental qualitativo dos meios físico, biótico e antrópico da área do lixão da cidade de Pombal no Estado da Paraíba.

\section{MATERIAL E MÉTODOS}

A área de estudo está localizada no município de Pombal, no estado da Paraíba, Brasil (Figura 1). O referido município está situado nas coordenadas geográficas $06^{\circ} 46^{\prime} 12^{\prime \prime}$ 'S e $37^{\circ} 48^{\prime} 07^{\prime \prime}$ 'W e a $388 \mathrm{~km}$ da capital do estado, João Pessoa (IBGE, 2010).

Figura 1. Localização do município de Pombal no Estado da Paraíba

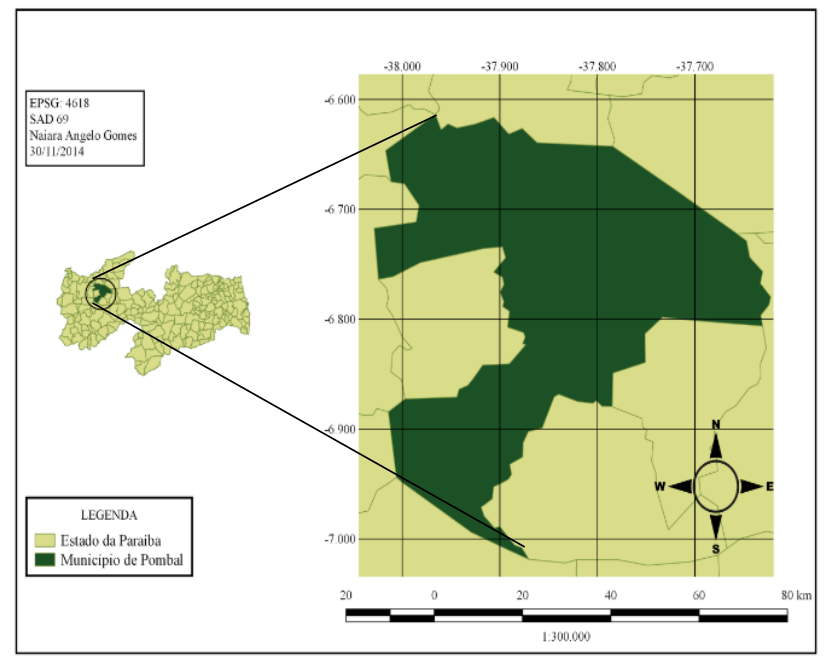

Fonte: Autores (2014)

A área do lixão está situada a aproximadamente $650 \mathrm{~m}$ do perímetro urbano de Pombal-PB e às margens da BR-230, principal rodovia de acesso a este município. O lixão possui uma área de aproximadamente 28,2 ha, recebe em média 180 toneladas de resíduos sólidos por mês e possui uma área útil de 12,2 ha (AZEVEDO, 2014).

Na Figura 2, observa-se o mapa de localização da zona urbana do município de Pombal-PB, com destaque para à área de estudo.

Figura 2. Localização do lixão da cidade de Pombal no Estado da Paraíba

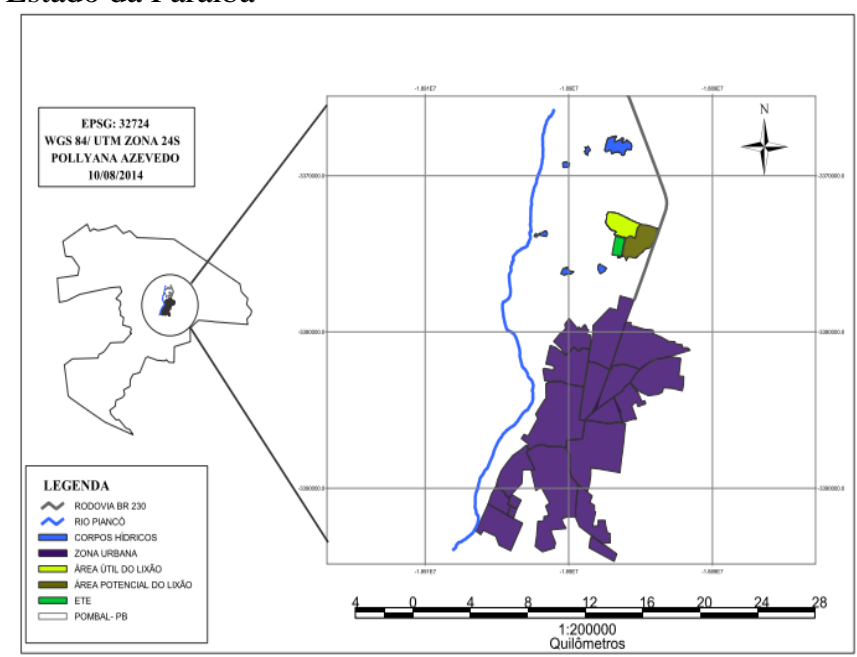

Fonte: Azevedo (2014) 


\section{Caracterização do Estudo}

Este estudo relata uma pesquisa explicativa e foi realizada por meio de consultas a órgãos públicos, pesquisas bibliográficas, visitas de campo e fotodocumentação, no período de setembro a dezembro do ano de 2014.

\section{Definição da Área de Influência do Estudo}

A Área de Influência Total (AIT) de um empreendimento ou atividade a ser abordada em um estudo ambiental compreende o espaço territorial de abrangência dos impactos ambientais. De forma geral, a AIT é dividida em Área de Influência Direta (AID) e Área de Influência Indireta (AII). Neste trabalho, foi convencionado que:

- Área de Influência Direta (AID): compreende a área útil e potencial do lixão, ou seja, a área que recebe diretamente os resíduos sólidos, e o seu entorno, englobando um raio de $200 \mathrm{~m}$ a partir da margem da área total do lixão.

- Área de Influência Indireta (AII): área que abrange parte da zona urbana do município de Pombal - PB, em um raio de $700 \mathrm{~m}$, e a que recebe os impactos ambientais indiretos causados pelo lixão.

Neste estudo, foi considerada apenas a AID, afetada diretamente pelas alterações ambientais negativas, principalmente as consideradas significativas, que acarretam a degradação dos componentes do ambiente.

A delimitação da AID foi realizada com base nas visitas "in loco", em que sua extensão foi definida por meio da observação das áreas vizinhas com ocorrência de resíduos sólidos do lixão.

Na Figura 3, apresentam-se imagens de satélite com a delimitação da Área de Influência Total (AIT) e respectivas áreas que a compõem.

Figura 3. Área de Influência Total (AIT) no lixão da cidade de Pombal no Estado da Paraíba
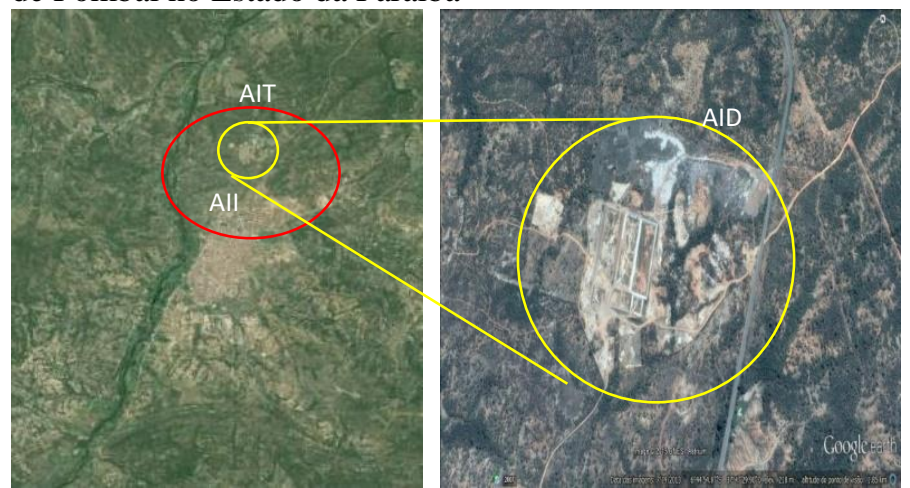

Fonte: Adaptado de Google Earth (2013)

\section{Diagnóstico Ambiental Qualitativo}

O diagnóstico ambiental qualitativo foi realizado apenas na área de influência direta, a partir da consulta a órgãos municipais competentes, pesquisas bibliográficas em estudos ambientais já realizados na área de estudo, visitas de campo e levantamento fotográfico. Dessa forma, foram identificadas, analisadas e descritas as características de interesse do estudo, relacionadas aos meios físico, biótico e antrópico, conforme apresentado na Tabela 1.
Tabela 1. Características ambientais descritas na Área de Influência Direta (AID)

\begin{tabular}{ll}
\hline Meio abiótico & Meio biótico \\
- Solo & - Flora \\
- Recursos hídricos & - Fauna \\
- Ar atmosférico & $\begin{array}{l}\text { Meio antrópico } \\
\text { - Paisagem }\end{array}$ \\
& - Perfil dos catadores do lixão \\
& Saública
\end{tabular}

\section{RESULTADOS E DISCUSSÃO}

\section{Meio Físico}

\section{Solo}

De acordo com Lima e Leite (2011), os solos do município de Pombal-PB apresentam predominância da Classe Luvissolos Crômicos (antes denominados Bruno Não Cálcico), que compreendem solos minerais, não hidromórficos, de textura média no horizonte A e argiloso no $B$ e ficam situados em localidades que apresentam basicamente relevo ondulado. Estes solos são caracterizados pela baixa profundidade, por fertilidade regular e alta erodibilidade.

$\mathrm{Na}$ AID, os solos apresentam revolvimento ou compactação em grande parte de sua área, exposição aos efeitos naturais (chuva, vento, radiação solar etc.), afloramento de rochas (Figura 4A) e, em alguns locais, encontram-se escarpados. Além disso, observam-se solos com focos erosivos e coloração avermelhada (Figura 4B).

Figura 4. Características do solo na área do lixão de PombalPB: A) Afloramento de rochas; B) Compactação e coloração avermelhada
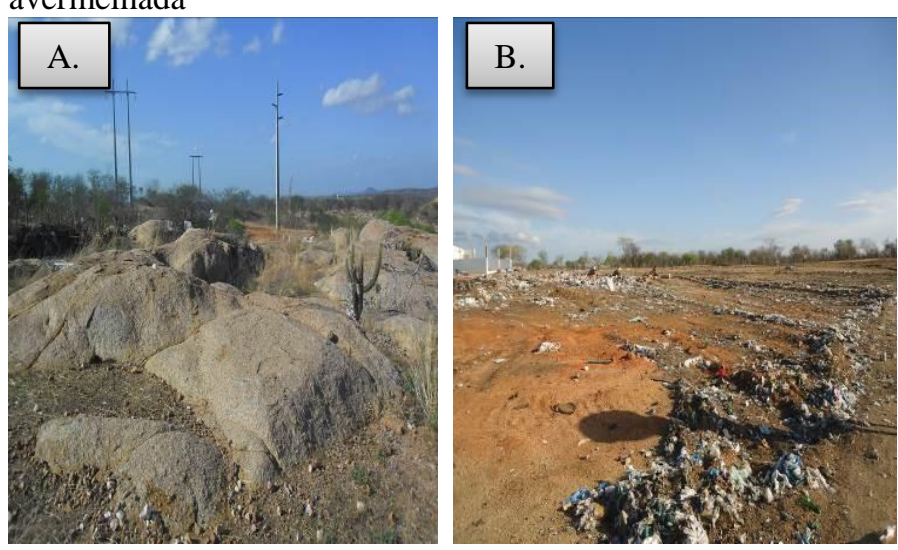

$\mathrm{Na}$ área do lixão, encontram-se resíduos sólidos, a exemplo de lâmpadas fluorescentes, pilhas e baterias, e, apesar de não terem sido realizadas análises qualitativas, presume-se que estes solos, provavelmente, apresentam contaminação por metais pesados, visto que, estes resíduos possuem em sua composição elementos tais como: mercúrio, chumbo, cádmio, zinco, manganês, lítio entre outros (AZEVEDO, 2014). Além disso, a exposição do solo na área de estudo, que não possui nenhum tipo de proteção - o que é típico de áreas de lixões -, pode conter a presença de subprodutos gerados no processo de biodegradação dos resíduos orgânicos.

O lixiviado é um desses subprodutos, e este líquido é altamente tóxico, com concentrações elevadas de DBO 
(Demanda Bioquímica de Oxigênio) e DQO (Demanda Química de Oxigênio), traços de metais dissolvidos e amônia (SILVA, 2012).

\section{Recursos Hídricos}

A área de estudo é caracterizada por possuir um curso d'água (riacho) (Figura 5) com vazão efêmera, localizado dentro da própria área do lixão, e dois reservatórios artificiais (barragens), localizados em sua proximidade, ambos de pequeno porte.

Figura 5. Corpo hídrico localizado dentro da área do lixão da cidade de Pombal, Paraíba

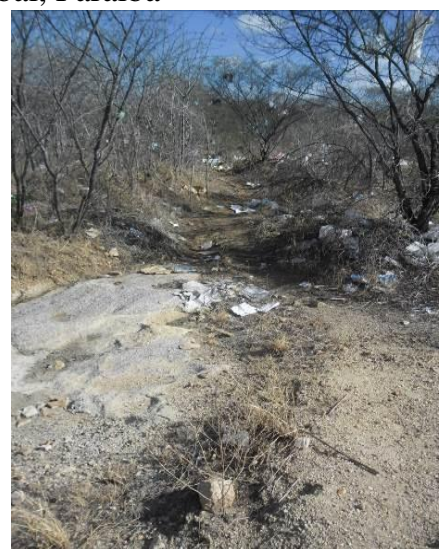

Fonte: Autores (2013)

Próximo da área do lixão encontra-se também o rio Piancó, situado a uma distância de aproximadamente $1100 \mathrm{~m}$ deste local. É importante destacar que, no período chuvoso, os canais de drenagem natural, principalmente o riacho, deságuam neste rio e, provavelmente, levam no escoamento o percolado do lixão (lixiviado), podendo assim, ocasionar uma possível poluição e/ou contaminação desse corpo d'água e um desequilíbrio nos ecossistemas aquáticos e terrestres do local.

Devido a inexistência de um sistema de captação, armazenamento e tratamento do lixiviado gerado no lixão, ocorre, provavelmente, sua infiltração no solo, que acaba poluindo e contaminando os corpos hídricos subterrâneos.

\section{Ar Atmosférico}

$\mathrm{O}$ ar atmosférico caracteriza-se por apresentar, provavelmente, poluição, devido à decomposição da matéria orgânica, que gera odores indesejáveis e gases poluentes. Um dos principais gases gerados é o metano $\left(\mathrm{CH}_{4}\right)$. Este gás é muito tóxico e contribui para o agravamento do aquecimento global.

Outra importante característica percebida no ar atmosférico foi a poluição e/ou contaminação resultante da "queima" do lixo, que ocorre semanalmente, a céu aberto, conforme apresentado nas Figuras 6A e 6B. Tal ação é realizada por um grupo de catadores que frequentam o local, com o propósito de diminuir a quantidade de resíduos existentes na área do lixão ou de fazer a sua limpeza (Figura 6A) e assim facilitar a separação dos materiais recicláveis.

$\mathrm{Na}$ queima dos resíduos, são gerados gases poluentes (Figura 6B) que afetam diretamente o ar atmosférico da área e a saúde dos moradores que residem, frequentam ou trabalham nas proximidades e no interior deste lixão, além dos moradores da zona urbana do município, onde se observou ainda, de forma cíclica, a ocorrência de poluição visual causada pela emissão de fumaça, conforme ilustrado nas Figuras 6C e 6D.

Figura 6. Queima de resíduos no lixão da cidade de Pombal, Paraíba: (A) Queima a céu aberto; (B) Geração de gases poluentes; (A, B, C e D) Poluição visual
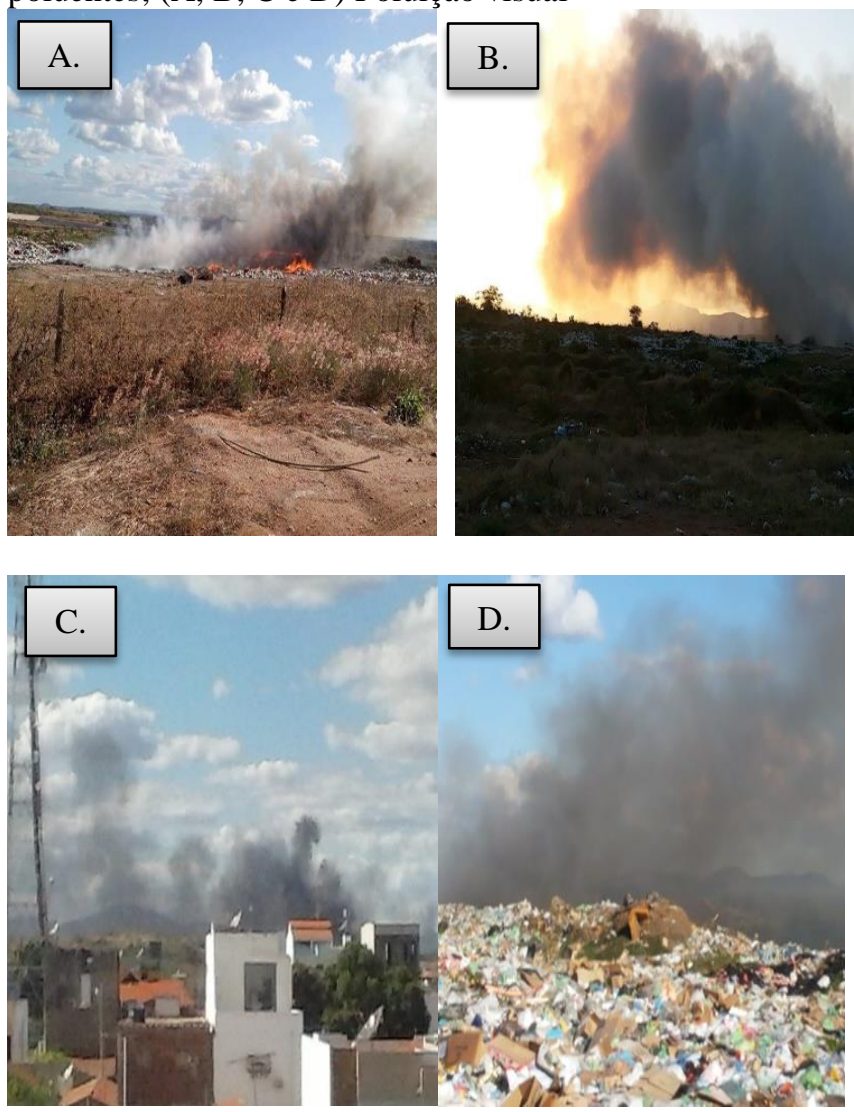

Fonte: Autores (2014)

De acordo com a Lei n. 12.305/2010, que trata da a Política Nacional de Resíduos Sólidos (BRASIL, 2010), em seu Art. 47, inciso III, "é proibido a queima de resíduos sólidos e rejeitos em local a céu aberto ou em recipientes, instalações e equipamentos não licenciados para essa finalidade". Ainda no Art. 47, no parágrafo $1^{\circ}$, cita-se que: Somente é possível a queima de resíduos ou rejeitos a céu aberto quando decretada emergência sanitária, desde que autorizada e acompanhada pelos órgãos competentes do Sistema Nacional do Meio Ambiente (SISNAMA), do Sistema Nacional de Vigilância Sanitária (SNVS) e, quando couber, do Sistema Unificado de Atenção à Sanidade Agropecuária (SUASA) (BRASIL, 2010, p. 18).

Portanto, a queima dos resíduos no lixão de Pombal-PB acontece de forma irregular, uma vez que é realizada sem a necessidade citada na referida lei e sem nenhum acompanhamento dos órgãos responsáveis, prejudicando, assim, os aspectos social, sanitário e ecológico do município.

\section{Paisagem}

A área de estudo, antes da degradação pela destinação inadequada dos resíduos sólidos, era composta por espécies vegetais típicas do bioma Caatinga que abrigavam, alimentavam e protegiam espécies animais nativas deste bioma. 
De acordo com Azevedo (2014), há 30 anos antes da implantação do atual lixão, moradores que residiam nos bairros próximos à área, já depositavam resíduos no local. Então, desde a sua implantação no ano de 1999, essa quantidade de resíduos tem aumentado de forma significante. Na Figura 7, é apresentada a situação do lixão nos anos de 2013 e 2014.

Figura 7. Paisagem da área do lixão da cidade de Pombal, Paraíba: A) 2013; B) 2014
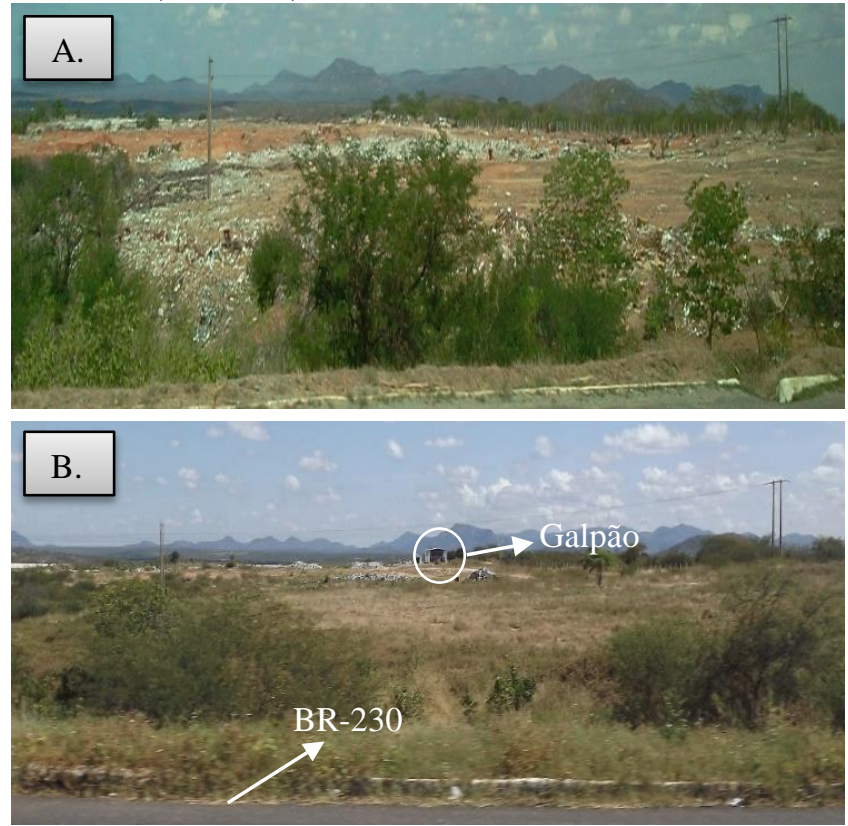

Fonte: Azevedo (2014)

Devido ao acúmulo de resíduos e à presença de catadores que utilizam a área como fonte de sobrevivência, observou-se uma alteração da paisagem, e ainda de vários outros impactos ambientais negativos, principalmente de ordem social e ecológica.

Como o lixão fica bem próximo da BR-230, isso ocasiona um forte impacto visual às pessoas que visitam a cidade de Pombal-PB, às que residem próximo a esse depósito e às que transitam por esse trecho da citada rodovia (AZEVEDO, 2014), sendo que, estas últimas ainda correm o risco de sofrerem acidentes, visto que, os resíduos ficam bem próximos dessa rodovia e atraem animais, tais como cães, mulas, porcos etc., além da diminuição da visibilidade devido, a fumaça gerada na queima dos resíduos.

Outro aspecto a destacar, é que ao comparar as Figuras $7 \mathrm{~A}$ e $7 \mathrm{~B}$, no que diz respeito à quantidade de resíduos acumulados sobre o solo nas proximidades da BR-230 (limite visto na base das fotografias), observa-se que esta quantidade é bastante visível na Figura 7A e pouco visível na Figura 7B. Isso ocorreu porque no ano de 2014 a "área útil" do lixão já havia se "deslocado" e se afastado da rodovia, devido à sua expansão (Figura 2). Outra mudança impactante na paisagem foi a construção do galpão dos catadores (Figura 7B).

\section{Meio Biótico}

As espécies vegetais encontradas na AID constituem-se basicamente de espécies típicas do bioma Caatinga, com exceção da Algaroba (Prosopis Juliflora) que é uma espécie exótica.
$\mathrm{Na}$ Tabela 2 e nas Figuras $8 \mathrm{~A}$ a $8 \mathrm{~F}$ encontram-se apresentadas as principais espécies vegetais identificadas na área de estudo.

Tabela 2. Espécies vegetais identificadas na área do lixão da cidade de Pombal, Paraíba

\begin{tabular}{cccc}
\hline Família & $\begin{array}{c}\text { Nome } \\
\text { científico }\end{array}$ & $\begin{array}{c}\text { Nome } \\
\text { popular }\end{array}$ & Figura \\
\hline $\begin{array}{c}\text { Fabaceae- } \\
\text { mimosoideae }\end{array}$ & $\begin{array}{c}\text { Mimosa } \\
\text { hostilis } \\
\text { Anadenanthera } \\
\text { colubrina }\end{array}$ & $\begin{array}{c}\text { Jurema-preta } \\
\text { branco }\end{array}$ & $8 \mathrm{~A}$ \\
\hline Leguminosae & $\begin{array}{c}\text { Prosopis } \\
\text { juliflora }\end{array}$ & Algaroba & $8 \mathrm{C}$ \\
\hline Cactaceae & $\begin{array}{c}\text { Cereus } \\
\text { jamacaru } \\
\text { Pilosocereus } \\
\text { gounelleii }\end{array}$ & Mandacaru & $8 \mathrm{D}$ \\
\hline
\end{tabular}

Figura 8. Espécies vegetais diagnosticadas na área do lixão da cidade de Pombal, Paraíba
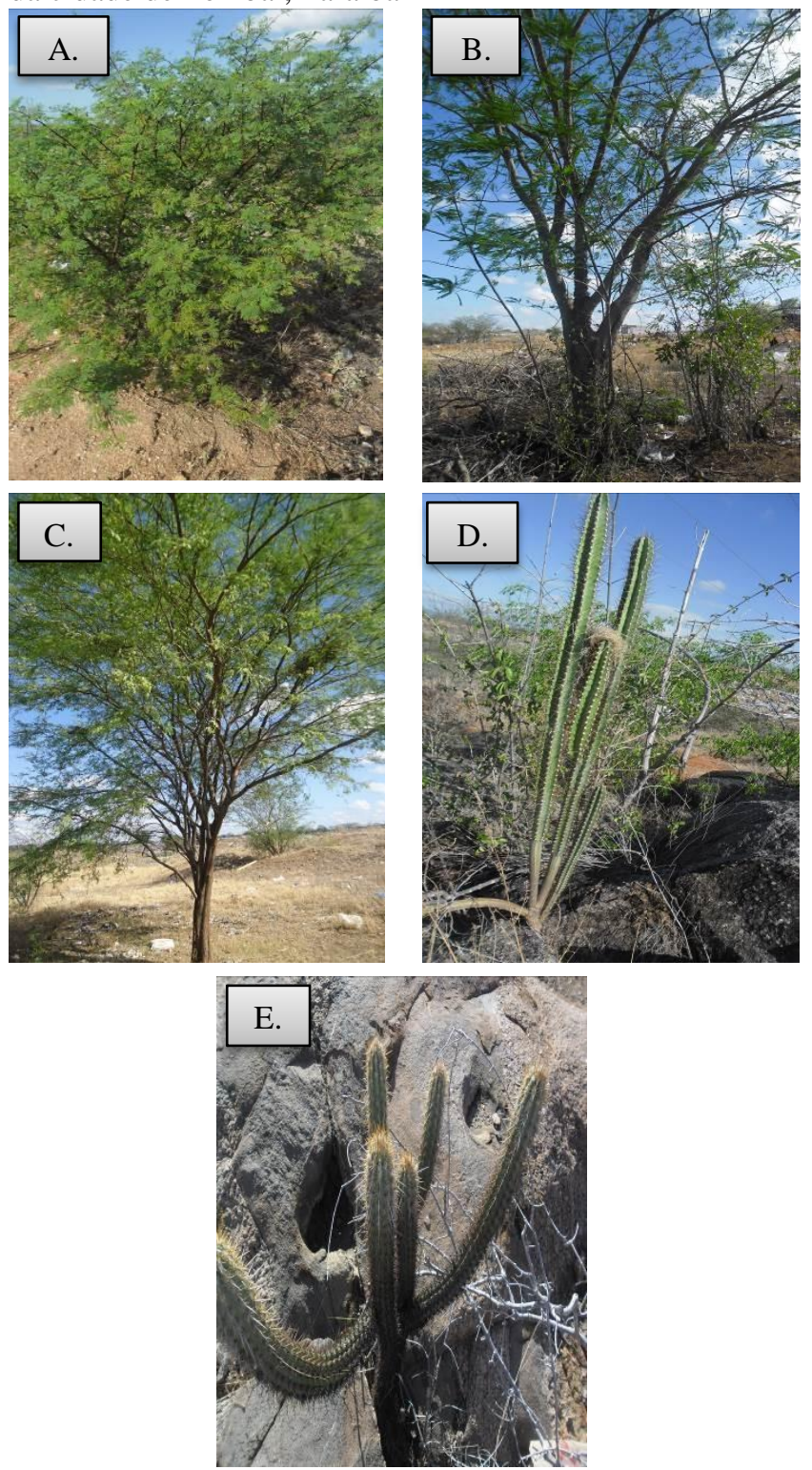

Fonte: Autores (2014) 
Em estudo realizado por Ismael et al. (2013), numa área pertencente ao município de Pombal-PB, verificou-se, a partir de um diagnóstico ambiental simplificado da flora local, que as principais espécies vegetais encontradas foram: juazeiro (Ziziphus joazeiro), xique-xique (Pilosocereus gounelleii), jurema-preta (Mimosa hostilis), mandacaru (Cereus jamacaru), pau-serrote (Hoffmanseggia falcaria), mufumbo (Combretum leprosum) e pereiro (Aspidosperma pyrifolium), praticamente, as mesmas espécies encontradas na área desse estudo.

Espécies como raposa, tatu-peba e guaxinim não foram observadas nas visitas "in loco". A ausência dessas espécies provavelmente foi observada devido ao aumento do desmatamento para a disposição dos resíduos e também à modificação do ambiente, que se tornou impróprio para a sobrevivência desses elementos da fauna.

\section{Meio Antrópico}

Um dos graves problemas identificados no lixão foi a presença de um grupo de catadores, pessoas adultas, que "trabalham" nessa área inóspita e em condições desumanas. Entre esses catadores, alguns moram na própria área e outros residem em áreas próximas a esta, sendo que, todos os dias eles se encontram e fazem a separação, acondicionamento e o armazenamento dos resíduos recicláveis. Sendo assim, o lixão de Pombal-PB é um "local de trabalho" para algumas pessoas que não possuem outra alternativa de sobrevivência.

Este grupo de catadores provavelmente não possui escolaridade e, conforme observado nas visitas de campo, "trabalham" em condições precárias, não utilizam equipamentos de proteção individual e dividem o ambiente fétido com micro e macrovetores, arriscando dessa forma a sua saúde e a vida.

$\mathrm{Na}$ área do lixão, há pouco tempo foi construído pela Prefeitura Municipal local um galpão para o armazenamento dos recicláveis, o que não deveria ser apropriado devido ao ambiente de "trabalho" ser totalmente insalubre, além do lixão ser uma atividade irregular e ambientalmente inadequada, sob os aspectos social, econômico e ecológico.

$\mathrm{O}$ acúmulo de resíduos no lixão atrai uma grande quantidade de micro e macrovetores, tais como: ratos, baratas, moscas, mosquitos, cachorros, gatos, bactérias, vírus etc., que podem ocasionar vários tipos de doenças, como micoses, leptospirose, diarreias, infecções entre outras, na população que reside na área de influência dessa atividade.

De acordo com Lima et al. (2011), em um estudo desenvolvido no lixão de São Vicente do Seridó-PB, constataram que a disposição inadequada dos resíduos sólidos urbanos pode acarretar várias doenças aos habitantes, como diarreias, dengue e febre, sendo este fato comprovado por $66,7 \%$ dos catadores, quando entrevistados sobre quais as doenças mais frequentes relacionadas ao lixão.

Um estudo realizado por Cavalcante e Franco (2007) no lixão de Jangurussu em Fortaleza - CE relatou que uma das principais doenças ocupacionais mencionadas por catadores foi a micose, aparecendo com maior frequência nas mãos e pés.

Neste sentido, os casos de doenças frequentes em catadores ou em pessoas que residem próximas a depósitos de lixo podem variar muito, visto que os resíduos possuem uma composição bastante heterogênea, mas todas as doenças relatadas nestes locais possuem uma consequência em comum: aumento dos gastos com saúde pública.
No caso do lixão de Pombal-PB, além das doenças já mencionadas que podem surgir ou aparecer nos catadores ou na população que reside no seu entorno, outro aspecto a ser levado em conta é a queima dos resíduos, que é ilegal e pode ocasionar doenças respiratórias na população.

\section{CONCLUSÕES}

O diagnóstico ambiental qualitativo dos meios físico, biótico e antrópico do lixão da cidade de Pombal indicou que todos os fatores ambientais estudados na área de influência direta encontram-se impactados negativamente, e grande parte, a exemplo do solo, do ar, da flora e fauna, apresentam alterações significativas e provável degradação.

Espera-se que os resultados desse estudo possam promover junto à Prefeitura Municipal local um incentivo para a elaboração de um conjunto de medidas que sirva de subsídio para a desativação do referido lixão, o que é previsto em lei federal (Lei n. 12.305/2010).

\section{REFERÊNCIAS}

ABRELPE. ASSOCIAÇÃO BRASILEIRA DE EMPRESAS DE LIMPEZA PÚBLICA E RESÍDUOS ESPECIAIS. Panorama de Resíduos Sólidos no Brasil 2014. Disponível em:

http://www.abrelpe.org.br/Panorama/panorama2014.pdf>.

Acesso em: 02 de ago. 2016.

AZEVEDO, P. B. Diagnóstico da degradação ambiental na área do lixão de Pombal-PB. 2014. 66 fls. Trabalho de Conclusão de Curso (Graduação em Engenharia Ambiental) Unidade Acadêmica de Ciências e Tecnologia Ambiental, Universidade Federal de Campina Grande, Pombal-PB. 2014.

BRASIL. Lei $\mathrm{n}^{\mathrm{o}}$ 12.305, de 2 de agosto de 2010. Institui a Política Nacional de Resíduos Sólidos; altera a Lei n⿳ํㅜㅇ.605, de 12 de fevereiro de 1998; e dá outras providências. Disponível

em:<http://www.planalto.gov.br/ccivil_03/_ato20072010/20/1 ei/112305.htm >. Acesso em: 15 de out. 2016.

BRASIL. Ministério do Meio Ambiente. Conselho Nacional do Meio Ambiente (CONAMA). Resolução n. 001, de 23 de janeiro de 1986. Dispõe sobre critérios básicos e diretrizes gerais para a avaliação de impacto ambiental. Disponível em: <http://www.mma.gov.br/port/conama/legiabre.cfm?codlegi= 23>. Acesso em: 20 de out. 2016.

CAVAlCANTE, S.; FRANCO, M. F. A. Profissão perigo: percepção de risco à saúde entre os catadores do Lixão do Jangurussu. Rev. Mal-Estar Subj. Fortaleza-CE, v. 7, n. 1, mar. 2007. Disponível em: $<$ http://pepsic.bvsalud.org/scielo.php?script=sci_arttext\&pid= $\mathrm{S} 151861482007000100012 \& \operatorname{lng}=\mathrm{pt} \& \mathrm{nrm}=\mathrm{iso}>$. Acesso em: 24 ago. 2016.

CONAMA. CONSELHO NACIONAL DO MEIO AMBIENTE. Resolução CONAMA n 001, de 23 de janeiro de 1986. Dispõe sobre procedimentos relativos ao Estudo de Impacto Ambiental e Relatório de Impacto ao Meio Ambiente (EIA-RIMA). Disponível em: < http://www.mma.gov.br/port/conama/res/res86/res0186.html> . Acesso em: 02 de set. 2016. 
IBGE. INSTITUTO BRASILEIRO DE GEOGRAFIA E ESTATÍSTICA. Cidades. 2010. Disponível em: <http://www.ibge.gov.br/cidadesat/painel/painel.php?codmun $=251210>$. Acesso em 02 de set. 2016 .

ISMAEL, F. C. M.; LEITE, J. C. A.; GOMES, N. A. MEDEIROS, W. S.; VALE, R. Identificação e avaliação dos impactos ambientais resultantes da erosão do solo na área do Campus da UFCG em Pombal-PB. Revista Verde de Agroecologia e Desenvolvimento Sustentável. v. 8, n.4, p. 8796, 2013.

LIMA, F. C.; LEITE, J. C. A. Estudo de avaliação e diagnóstico dos impactos ambientais dos impactos ambientais resultantes da implantação do Campus universitário da UFCG em Pombal-PB. 2011. 16 fls. Projeto PIBIC - Unidade Acadêmica de Ciências e Tecnologia Ambiental, Universidade Federal de Campina Grande, Pombal-PB. 2011.
LIMA, F. C.; LIMA, V. C.; LIMA, S. C.; SOBRAL, A.; LEITE, J. C. A. Diagnóstico da gestão dos resíduos sólidos urbanos: estudo de caso de São Vicente do Seridó-PB. In: II Congresso Brasileiro de Gestão Ambiental, 2011, LondrinaPR. 2012. 5 p.

LUCENA, K. P. Diagnóstico ambiental simplificado da área do lixão de Pombal-PB. 2013. 28 fls. Relatório Final de Estágio Supervisionado - Unidade Acadêmica de Ciências e Tecnologia Ambiental, Universidade Federal de Campina Grande, Pombal-PB. 2013.

SILVA, A. S. Avaliação do potencial tóxico dos resíduos sólidos urbanos da cidade de Campina Grande-PB. 2012. 139 fls. Dissertação (Engenharia Civil e Ambiental), Universidade Federal de Campina Grande, 2012. 